\title{
Tolerance Verification of an Industrial Assembly using Computed Tomography
}

\author{
Stolfi, Alessandro; De Chiffre, Leonardo; Regi, Francesco
}

Published in:

Proceedings of the 11th International Conference on Multi-Material Micro Manufacture (4M2016)

Publication date:

2016

Document Version

Publisher's PDF, also known as Version of record

Link back to DTU Orbit

Citation (APA):

Stolfi, A., De Chiffre, L., \& Regi, F. (2016). Tolerance Verification of an Industrial Assembly using Computed Tomography. In Proceedings of the 11th International Conference on Multi-Material Micro Manufacture (4M2016): co-organised with 10th International Workshop on Microfactories (IWMF2016) Research Publishing Services.

\section{General rights}

Copyright and moral rights for the publications made accessible in the public portal are retained by the authors and/or other copyright owners and it is a condition of accessing publications that users recognise and abide by the legal requirements associated with these rights.

- Users may download and print one copy of any publication from the public portal for the purpose of private study or research.

- You may not further distribute the material or use it for any profit-making activity or commercial gain

- You may freely distribute the URL identifying the publication in the public portal 


\title{
Tolerance Verification of an Industrial Assembly using Computed Tomography
}

\author{
Alessandro Stolfi, Leonardo De Chiffre, Francesco Regi \\ Technical University of Denmark, Department of Mechanical Engineering, Section of Manufacturing Engineering, \\ Produktionstorvet Building 425, Kgs. Lyngby Denmark, \\ email: alesto@mek.dtu.dk, Idch@mek.dtu.dk, s141828@student.dtu.dk
}

\begin{abstract}
This paper reports on results of tolerance verification of a multi-material assembly by using Computed Tomography (CT). The workpiece comprises three parts which are made out of different materials. Five different measurands were inspected. The calculation of measurement uncertainties was attempted by way of a ball plate. Comparison between CT and results from a traditional coordinate measuring machine was also involved in this study.
\end{abstract}

Keywords: Computed tomography, tolerance verification, assembly, metrology

\section{Introduction}

Small components are widespread in innovative industrial products. Such parts are extremely complex and often demand complex strategy measurements and multiple setups. Computed Tomography (CT) provides a new tool for coping with the complexity, establishing a holistic dimensional metrology on a workpiece [1-2]. The use of X-rays as sensor allows penetrating a large variety of materials and enabling the complete surface measurement of small and internal features which would be inaccessible using other measuring instruments. Just scanning a workpiece once, high information density can be obtained, by making savings on the amount of measurements required, as well as increasing the reliability of measurements. CT removes the physical interaction with the parts, minimizing the workpiece deformations and the costs associated with design and manufacturing of dedicated fixturing systems. Assembly inspection represents the most important feature of CT allowing to detect undesired gaps and interferences between individual components of the assembly. These are significant advantages over the traditional coordinate measuring machines (CMMs). On the contrary, the use of CT for dimensional measurements does not provide the same level of traceability as is the case with a CMM. In the present work, tolerance verification of a multi-material industrial part is reported. An assembly including two polymers and metal pin was investigated. The work also presents an uncertainty estimation for CT measurements.

\subsection{Workpiece and its measurands}

The assembly under investigation is an industrial component produced by a Danish hearing aid manufacturer (see Fig.1). The workpiece comprises three parts: shell, battery holder and pin joint. Information on each part is provided in table 1. From the table, it can be seen that the shell and battery holder present very similar attenuation values, $\mu$, within the range of powers usually used for small polymer parts (i.e. 75 to $120 \mathrm{KV}$ ). This similarity may cause some problems if the contrast at the interface is poor. Thermal properties of the two materials are different which may also lead to deformation problems. The shell and the holder are assembled by means of cantilever snap joints.

Table 1

Information on parts in the assembly. CTE: coefficient of thermal expansion.

\begin{tabular}{|c|c|c|c|}
\hline \multicolumn{2}{|c|}{} & \multicolumn{2}{c|}{ Component } \\
\cline { 2 - 4 } material & Unit & $\begin{array}{c}\text { PBT } \\
\text { (Polybutylene } \\
\text { terephthalate) }\end{array}$ & $\begin{array}{c}\text { POM } \\
\text { (Polyoxymethylene) }\end{array}$ \\
\hline Density & $\mathrm{g} / \mathrm{cm}^{3}$ & 1.50 & 1.42 \\
\hline$\mu$ & $\mathrm{cm}^{-1}$ & $0.260 \pm 15 \%$ & $0.247 \pm 10 \%$ \\
\hline CTE & $10^{-6} \mathrm{~K}^{-1}$ & 70 & 110 \\
\hline
\end{tabular}

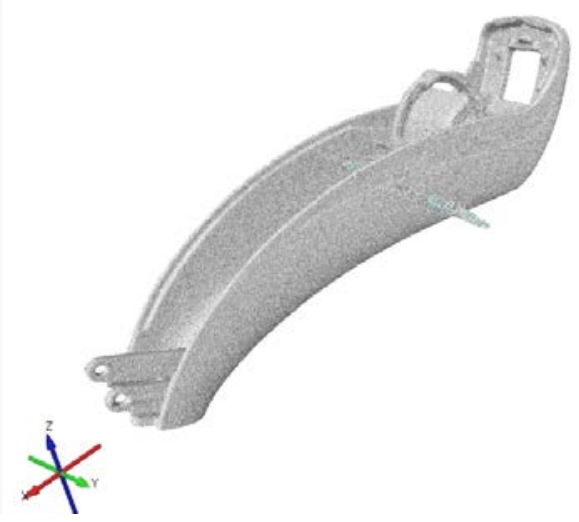

Fig. 1. 3D reconstruction depicting the assembly. 
Five measurands (four dimensional and one geometrical) were selected. These are: external length $(E)$, internal length $(I)$, thickness of left wall (T1), thickness of right wall (T2), flatness of bottom surface of the holder $(\mathrm{F})$.

Nominal dimensions and their tolerances are reported as follows: $E=7.40 \pm 0.10 \mathrm{~mm}, I=6.40 \pm$ $0.10 \mathrm{~mm}, T 1=0.55 \pm 0.10 \mathrm{~mm}$ and $T 2=0.55 \pm 0.10$ $\mathrm{mm}$, and $F=0.10 \mathrm{~mm}$. Because of a confidentiality agreement with workpiece manufacturer, all presented tolerances do not reflect the real tolerances of the components considered.

\section{Measurements on CT scanner}

Measurements were conducted on a Nikon XT H 225 CT available at DTU. Scanning parameters are reported in table 2. The workpiece was tilted and mounted in a low absorption fixture made out of polystyrene (PS), presenting low predisposition to yield imaging artefacts at the power used. After having mounted the part in the fixture, the fixture was stabilized for 30 minute to avoid material relaxation thereby preventing workpiece slippage while scanning.

The workpiece was scanned in two different positions shifted relative to each other by 180 degrees. This strategy took inspiration from the reversal methods developed for traditional CMMs [3]. By using this procedure, source drift and detector defects may be minimized, despite the absence of full symmetry of the workpiece. A total of 4 scans were performed. A cupper target was set for this investigation, instead of the tungsten target normally used, because of its advantages in ensuring better contrast at low powers. Due to the high magnification used, it was also necessary to reduce the focus spot in order not to strongly blur the projections. Physical beam hardening correction was conducted by means of $0.10 \mathrm{~mm}$ thick aluminium, having an atomic number bigger than the materials of the workpiece to be scanned.

Table 2

Overview of scanning parameters.

\begin{tabular}{|c|c|c|}
\hline Parameter & Unit & Value \\
\hline X-ray tube voltage & $\mathrm{kV}$ & 80 \\
\hline X-ray tube current & $\mu \mathrm{A}$ & 140 \\
\hline Corrected voxel size & $\mu \mathrm{m}$ & 19 \\
\hline Magnification factor & & 10 \\
\hline No. of projections & & 1000 \\
\hline No. of image for projection & & 1 \\
\hline Pixel size & $\mu \mathrm{m}$ & 127 \\
\hline Integration time & $\mathrm{s}$ & 2 \\
\hline Scanning time & $\min$ & 33 \\
\hline
\end{tabular}

Detector calibration was done by using a total of 256 projections evenly distributed over four different power levels, with 64 projections per level. Just few power levels were sufficient due to the limited broadness of the X-ray spectrum used and the constant absorption values of the materials across the entire spectrum.

Scale error correction of the CT scanner was carried out using a CT ball plate [4], as the scanned used is not meant for metrology. In order that the scale error correction was effective, none of the scanning parameters was modified. This caused that not the whole plate was imaged but just a portion of it, which was however sufficient for the correction. The scale correction factor was found to be 0.9995, which physically means that distances are overestimated using CT. The temperature in the cabinet during scanning was $23^{\circ} \mathrm{C} \pm 1^{\circ} \mathrm{C}$. The measurement results were corrected for thermal offsets by using a linear model. Residual thermal effects were taken into account for measurement uncertainty estimations.

Image artefacts in the form of streak artefacts and cupping effects were noticed in the reconstructed images close to the metal pin. Nevertheless the artefacts were assumed to be of limited influence on the results. No workpiece displacement during measurement was observed by superimposing the last projection onto the first one. Fig 2 shows the grey value distribution describing the assembly imaged. It can be observed that the distribution is very compressed and none of material peaks appears to be well-defined. This condition is most probably due to the fact that the component materials present very similar X-ray absorption values but also that the amount of material being penetrated was too small to yield a more spread histogram.

Surface determination was based on a local thresholding method implemented in VG studio Max 2.2.6. This method currently represents the state-ofthe-art tool for segmenting CT data sets allowing to reach about $1 / 10$ of a voxel in terms of measurement uncertainty [5]. The surface was done by manually selecting the grey values belonging to the battery holder on the reconstructed images from different views. Sensitivity analysis was conducted to take into account the effect of the noise on the surface determination.



Fig. 2. Histogram of gray values of the reconstructed volume. The red line represents the starting point for the surface determination.

Evaluations were performed using VG studio Max 2.2.6 on the voxel model. The measurands were least square fitted as follows:

- External length (E) defined as a distance between two parallel planes created on the flat surfaces by fitting approximately 1000 points,

- Internal length (I) defined as a distance between two small parallel planes created by fitting approximately 1000 points,

- $2 \mathrm{x}$ wall thickness (T1, T2): they are defined as a distance between two parallel planes created on the inner and outer surface of the shell. A number of 1000 
points were used per plane. Each thickness is quantified as the distance of the two representative points on two fitted planes;

- Flatness $(F)$ is measured fitting approximately 1000 points. The points were all taken away from the edges of the holder. Flatness is calculated using $95 \%$ of fitted points.

Each feature was inspected using two different fitting gradients [6] $\left(5^{\circ}\right.$ and $\left.10^{\circ}\right)$ and then the results were averaged. This strategy usually permits to discard points which lay at different angulations with respect to the fitted surface. The evaluation time was estimated to be $20 \mathrm{~min}$.

Measurement uncertainties for CT measurements,

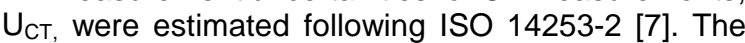
formula for uncertainty estimation for CT measurements is given by equation 1

$$
U_{C T}=K * \sqrt{u_{r}^{2}+u_{p}^{2}+u_{T}^{2}+u_{\text {noise }}^{2}+u_{d a t u m}^{2}}
$$

Here, $k$ is the coverage factor ( $k=2$, for a coverage interval of $95 \%), u_{r}$ is the standard uncertainty of the artefact used for the scale error correction, $\left(u_{r}=U_{c a l} / k\right.$, where $U_{\text {cal }}$ is the expanded calibration uncertainty for the CT ball plate [4]). For flatness measurements, the form error of the spheres was used; $u_{p}$ is the standard uncertainty of the measurement procedure carried out on the workpiece. This contribution was quantified as the standard deviation of four 3D comparisons; $u_{T}$ is the evaluation of standard uncertainty due to the temperature variability $\left( \pm 1^{\circ} \mathrm{C}\right)$ by assuming a Udistribution [8]; $u_{\text {noise }}$ is the standard uncertainty due to the noise. It was quantified using the standard deviation of measurements carried out at two thresholding levels. The first level was based on the mean values of the background distribution, while the second one on its biggest grey value. Information on grey value distribution was gathered from 2D projections; $u_{\text {datum }}$ is the uncertainty contribution due to the repeatability of the datum system, based upon experience [9]. The uncertainty budget for each feature is shown in Table 3 . The uncertainty values were all estimated to be less than $13 \mu \mathrm{m}$ with noise as major uncertainty contribution. A good repeatability was generally achieved, even for flatness measurements, as it can be noticed from standard uncertainty $u_{p}$. Some improvements of $\mathrm{CT}$ repeatability can be achieved by reconditioning the source before scanning in order to avoid thermal drifts.

Table 3

Uncertainty budget for CT measurements. All values are in $\mu \mathrm{m}$.

\begin{tabular}{|c|c|c|c|c|c|c|}
\hline \multirow{2}{*}{$\begin{array}{c}\text { Uncertainty } \\
\text { contribution }\end{array}$} & \multirow{2}{*}{ Symbol } & \multicolumn{5}{|c|}{ Measurands } \\
\cline { 3 - 7 } & & $\mathrm{E}$ & $\mathrm{I}$ & $\mathrm{T} 1$ & $\mathrm{~T} 2$ & $\mathrm{~F}$ \\
\hline Instrument & $\mathrm{u}_{\mathrm{cal}}$ & 1.2 & 1.2 & 1.2 & 1.2 & 3.0 \\
\hline Procedure & $\mathrm{u}_{\mathrm{p}}$ & 2.3 & 2.1 & 2.0 & 1.5 & 3.0 \\
\hline Temperature & $\mathrm{u}_{\mathrm{T}}$ & 0.2 & 0.2 & - & - & - \\
\hline Noise & $\mathrm{u}_{\text {noise }}$ & 2.5 & 2.5 & 2.5 & 2.5 & 4.0 \\
\hline
\end{tabular}

\begin{tabular}{|c|c|c|c|c|c|c|}
\hline Datum & $\mathbf{u}_{\text {datum }}$ & 2.2 & 2.2 & 2.2 & 2.2 & - \\
\hline $\begin{array}{c}\text { Expanded } \\
\text { uncertainty }\end{array}$ & $\mathbf{U}_{\mathbf{9 5} \%}$ & $\mathbf{9}$ & $\mathbf{9}$ & $\mathbf{8}$ & $\mathbf{8}$ & $\mathbf{1 3}$ \\
\hline
\end{tabular}

The measurement uncertainty statements were according to equation 2

$$
\mathrm{U}_{\mathrm{CT}}=\mathrm{K} * \sqrt{\mathrm{u}_{\mathrm{r}}^{2}+\mathrm{u}_{\mathrm{p}}^{2}+\mathrm{u}_{\mathrm{T}}^{2}} \text {. }
$$

Where $u_{r}$ is the standard uncertainty associated with material standard (a ring reference artifact and a flat glass); $u_{p}$ is the Type A evaluation of standard uncertainty of the measurement procedure, based on five repeated measurements; $u_{T}$ is the evaluation of standard uncertainty due to the temperature variability $\left( \pm 1^{\circ} \mathrm{C}\right)$ assuming a U-distribution. Uncertainty contributions and expanded uncertainties are reported in table 4

\section{Measurements on CMM}

The CMM measurements were performed using a Zeiss OMC 850 in a temperature-controlled laboratory $\left(20 \pm 1^{\circ} \mathrm{C}\right)$. A $10-\mathrm{mm}$-long probe equipped with a probe of a diameter of $0.8 \mathrm{~mm}$ was used for all the measurements. Measurements were all conducted using $0.10 \mathrm{~N}$ as probing force. The CMM evaluations were made with Calypso 5.4 software from Zeiss using a least square fit. The part was glued on a flat support. The programming time required $40 \mathrm{~min}$, while the measuring time was quantified to be $3.5 \mathrm{~min}$. The fixturing time required more than two hours, including the time for hardening the glue. A total of three hours were necessary for measuring the part.

Table 4

Uncertainty budget for CMM measurements. All values are rounded and expressed in $\mu \mathrm{m}$.

\begin{tabular}{|c|c|c|c|c|c|c|}
\hline \multirow{2}{*}{} & & \multicolumn{5}{|c|}{ Measurands } \\
\cline { 3 - 7 } & & $\mathrm{E}$ & $\mathrm{I}$ & $\mathrm{T} 1$ & $\mathrm{~T} 2$ & $\mathrm{~F}$ \\
\hline Instrument & $\mathrm{u}_{\mathrm{cal}}$ & 1.3 & 1.3 & 1.0 & 1.0 & 1.3 \\
\hline Procedure & $\mathrm{u}_{\mathrm{p}}$ & 0.1 & 0.1 & 0.1 & 0.1 & 0.1 \\
\hline Temperature & $\mathrm{u}_{\mathrm{T}}$ & 0.2 & 0.2 & - & - & - \\
\hline $\begin{array}{c}\text { Expanded } \\
\text { uncertainty }\end{array}$ & $\mathbf{U}_{95 \%}$ & $\mathbf{2 . 5}$ & $\mathbf{2 . 5}$ & $\mathbf{2}$ & $\mathbf{2}$ & $\mathbf{2 . 1}$ \\
\hline
\end{tabular}

\section{Results and discussion}

Results of geometrical and dimensional tolerances of the workpiece are reported in table 5 . Mean values, uncertainty values, nominal values and tolerance values are reported in the table for each measurand. The measurement results along with their estimated uncertainties obtained for the workpiece comply within the virtual specifications. The uncertainties estimated yielded uncertainty-to-tolerance ratio, $U / T$, ratios [10] being all lower than $13 \%$ for all selected measurands, as reported in table 6 . This means that the 
measurement uncertainties do not strongly reduce the conformance zone [11] and therefore the measuring process $(\mathrm{CT})$ is adequate.

Table 5

Average value, $X$, expanded uncertainty, $U_{95 \%}$, nominal value, $N$, and tolerance limit, $T$, for each measurand. All values are rounded and expressed in $\mathrm{mm}$.

\begin{tabular}{|c|c|c|c|c|}
\hline Measurand & $\mathrm{X}$ & $\mathrm{U}_{95 \%}$ & $\mathrm{~N}$ & $\mathrm{~T}$ \\
\hline $\mathrm{E}$ & 7.420 & 0.009 & 7.415 & 0.05 \\
\hline $\mathrm{I}$ & 6.318 & 0.009 & 6.322 & 0.05 \\
\hline $\mathrm{T} 1$ & 0.557 & 0.008 & 0.550 & 0.05 \\
\hline $\mathrm{T} 2$ & 0.548 & 0.008 & 0.550 & 0.05 \\
\hline $\mathrm{F}$ & 0.020 & 0.013 & 0 & 0.05 \\
\hline
\end{tabular}

Table 6

Uncertainty-to-tolerance ratio, $\mathrm{U} / \mathrm{T}$, and available conformance zone, $\mathrm{C}$, per measurands. All values in $\%$.

\begin{tabular}{|c|c|c|}
\hline Measurand & U/T & C \\
\hline E & 8 & 84 \\
\hline I & 8 & 84 \\
\hline T1 & 9 & 82 \\
\hline T2 & 9 & 82 \\
\hline F & 13 & 74 \\
\hline
\end{tabular}

In order to judge the agreement between CMM and CT measurements, the $E_{n}$ value normalised with respect to the estimated uncertainty was computed [12]. If $\left|E_{n}\right|<1$ the quality of the measurement result is acceptable, while it is not acceptable if $\left|E_{n}\right| \geq 1$. This analysis confirmed the agreement between the measuring equipment with $E_{n}$ values all below 0.40 . Bias values in the order of $1 / 5$ th of the corrected voxel size were registered. The limited systematic errors can be explained by the material of the part itself. Low density materials yields more homogeneous grey value distributions. The more homogeneous grey values, the more accurate surface determination and measurements. Moreover, the short penetration lengths and the complete absence of beam hardening enabled to have a surface determination at the same level for inner and outer features. As a consequence the thickness measurements show almost no bias errors. The use of the reversal method and the different fitting gradients also played a role in the measurements. For example without averaging the results of two different fitting gradients, bias values would increase of $4.5 \mu \mathrm{m}$ for the external and internal length measurements. Comparing the measuring time, The CMM inspection lasted less than the CT one, which required a total of 5 CT scans, including the scan of the ball plate. Faster CT inspections can be obtained by further tuning the scanning parameters or by using a CT designed for metrology.

\section{Conclusions}

This paper has presented the results of tolerance verification of a small assembly from a hearing aid device. CT uncertainties were quantified between 8 $\mu \mathrm{m}$ and $13 \mu \mathrm{m}$, depending on the measurand, with noise as dominant uncertainty factor. Bias values below $1 / 5$ th of the corrected voxel size were recorded. CT measurements, based on four reproducible measurements on the same part, fulfilled the tolerance specifications for the selected geometrical and dimensional tolerances. Uncertainties estimated yielded conformance zones up to $84 \%$ of the tolerance limits considered.

\section{Acknowledgements}

The research leading to these results has received funding from the People Programme (Marie Curie Actions) of the European Union's Seventh Framework Programme (FP7/2007-2013) under REA grant agreement no. 607817 INTERAQCT. The authors would like to acknowledge Jakob Rasmussen in connection with the CMM measurements.

\section{References}

[1] Kruth, J.P., Bartscher, M, Carmignato, S., Schmitt, R., De Chiffre L, Weckenmann A., 2011, Computed tomography for dimensional metrology, CIRP Annals - Manufacturing Technology; 60: 821-842.

[2] De Chiffre, L., Carmignato, S., Kruth, J.P., Schmitt, R., Weckenmann, A., 2014, Industrial applications of computed tomography. CIRP Annals Manufacturing Technology; 63: 655-677.

[3] Evans, C. J., Hocken, R. J., Estler, W. T., 1996, Self-Calibration: Reversal, Redundancy, Error Separation, and 'Absolute Testing'. CIRP Annals Manufacturing Technology, 45(2), 617-634.

[4] Müller, P., 2013, Coordinate Metrology by Traceable Computed Tomography. Ph.D. thesis, Technical University of Denmark (DTU), Kgs. Lyngby, Denmark.

[5] Borges de Oliveira, F., Stolfi, A., Bartscher, M., De Chiffre, L., 2016, Experimental investigation of surface determination process on multi-material components for dimensional computed tomography. Case Studies in Nondestructive Testing and Evaluation.

[6] Volume Graphics GmbH, 2013, VG Studio Max 2.2 Reference Manual, Heidelberg.

[7] ISO 14253-2: 2011 - Geometrical product specifications (GPS) - Inspection by measurement of workpieces and measuring equipment - Part 2: Guidance for the estimation of uncertainty in GPS measurement, in calibration of measuring equipment and in product verification.

[8] IEC Guide 98-3: 2008 - Uncertainty of measurement - Part 3: Guide to the expression of uncertainty in measurement.

[9] Stolfi, A., Thompson, M.K., Carli, L., De Chiffre, L., 2016, Quantifying the Contribution of PostProcessing in Computed Tomography Measurement Uncertainty. Procedia C I R P.

[10] Pereira, P.H., Hocken, R.J., 2011, Coordinate Measuring Machines and Systems. CRC Press.

[11] ISO 14253-1: 2013 - Geometrical product specifications (GPS) -- Inspection by measurement of workpieces and measuring equipment -- Part 1: Decision rules for proving conformity or nonconformity with specifications.

[12] ISO/IEC-17043. Conformity assessment, General requirements for proficiency testing. 2010. 